\title{
EFFECT OF DENTURE ADHESIVES ON SURFACE ROUGHNESS OF DENTURE BASE MATERIALS AND ITS RELATION TO CANDIDA ALBICANS ADHESION
}

\author{
Mahmoud Darwish Mohamed * and Said Daboor **
}

\begin{abstract}
Objectives: Candida-associated denture stomatitis is the most prevalent form of oral candidiasis affecting $65 \%$ of denture wearers. Continuous use of denture adhesives may affect the surface roughness of the denture material and may contribute to Candida adhesion. This study aimed to investigate surface roughness of two chemically different denture materials after exposure to denture adhesives and its relation to in vitro adhesion of Candida albicans.
\end{abstract}

Materials and Methods: Five groups of both PMMA and UDMA specimens (10 mm 10 $\mathrm{mm} 2 \mathrm{~mm}$ ) were prepared (10 specimens in each group). Specimens were immersed in Corega Cream (group 1), Corega Powder (group 2), Olivafix cream (group 3), Protefix cream (group 4) and distilled water (group 5). Specimens were tested for surface roughness, and in vitro Candida albicans adhesion.

Results: The results showed that Corega cream had statistically significant effect on surface roughness of both types of resins $(P<0.05)$. On the other hand the other three types of denture adhesive and distilled water had no statistically significant effect on surface roughness $(P>0.05)$.The differences in the Candida count between the UDMA specimens were not statistically significant. On the other hand the Candida count of Corega cream exposed group was statistically significant if compared with other groups in the PMMA resin specimens. The differences in the Candida count between the specimens of both resin groups were statistically non-significant $(P>0.05)$

Conclusions: Exposure to Corega cream denture adhesives may induce changes in surface roughness of denture base materials. Candida albicans adhesion is not necessarily increased on denture base materials that are exposed to denture adhesives.

KEY WORDS: Denture base, denture adhesives, Candida albicans.

* Lecturer of Removable Prosthodontics, Faculty of Dentistry, Suez Canal University, Ismailia, Egypt.

** Microbiology- National Institution of Oceanography and Fisheries, Cairo- Egypt. 


\section{INTRODUCTION}

Candida albicans (CA) is considered one of the most opportunistic micro-organisms that can cause mucosal fungal infections seen in man. It is a commensal in the oral cavity of $45-65 \%$ of healthy individuals, and may increases to $60-100 \%$ in denture wearers. ${ }^{1-3}$

Presence of denture in the oral cavity is one of the local factors that may trigger Candida infection. ${ }^{4}$ there is a vast body of confirmations indicating that Candida is able to adhere to acrylic resin dentures. Candida adhesion is the first step that may lead to progression of the infectious process and that may essentially result in varying degrees of denture stomatitis of the adjacent mucosa. ${ }^{5-7}$ Candida adheres directly or by a layer of denture plaque to denture bases, without this adherence, microorganisms would be removed from the oral cavity when saliva or food is being swallowed. ${ }^{8,9}$ Many factors related to the acrylic resin denture bases such as chemical composition, surface charge, surface free energy, hydrophobicity, as well as surface roughness have been implicated as major factors in Candida adhesion as was discussed by several studies in literature. ${ }^{10-13}$

Surface roughness of the denture base materials is one of the physical properties that may be changed as a result of surface degradation. There are many studies concerning surface degradation of the acrylic polymers as well as factors affecting surface roughness of the dental materials inside the oral cavity. ${ }^{14-20}$ This is because the surface roughness is considered one of the determinant factors in the clinical life span of the dental prosthesis. ${ }^{21}$ It directly influences micro-organisms initial adherence to surfaces, biofilm formation, and Candida species colonization. Materials with higher surface roughness mostly show higher yeast numbers. ${ }^{22}$

Denture adhesives (DA) are present in various formulations such as powders, pastes or cream for soluble adhesives and strips or cushion for insoluble adhesives. Large number of denture wearers regularly use DA as a way to improve denture retention, stability and function. ${ }^{23}$ Some properties should be available in the DA, like easy application and removal by the patient, appropriate flavor and consistency, not alter or deteriorate the denture material, and not enhance bacterial and fungal growth. ${ }^{24,25}$

Many researchers have examined the interactions between DA and oral microbiota, but the results were conflicting and debatable. Early in 1971, In vitro study done by Stafford and Russell showed that some DA supported CA growth, inducing hyphal formation. ${ }^{26}$ Others have suggested that DA possessed antifungal activity. ${ }^{27}$ Furthermore, two in vivo studies suggested that DA did not significantly alter the oral microbiota over a 14-day trial period. ., 28 Sampaio-Maia et al (2012) concluded from their in vitro study that some DA showed microbial contaminations and some had significant inhibitory effect on CA growth. ${ }^{29}$

The continuous using of DA could compromise the surface properties of the denture base resins enhancing microorganism adhesion. Moreover, the denture surface can act as a microorganism reservoir facilitating denture user re-infection. ${ }^{30}$

Up to our knowledge, there are no studies that have investigated both the effect of DA on the surface roughness of denture base materials; upon which it is applied, and the relation to CA adhesion.

Therefore, this in vitro study aimed to evaluate and compare the surface roughness of polymethylmethacrylate PMMA and urethane dimethacrylate UDMA denture base resins after application of four commercially available DA and investigate the relation to $\mathrm{CA}$ adhesion. The null hypothesis to be tested is that DA will have no impact on surface roughness of tested denture base resins, and CA adhesion as well. 


\section{MATERIALS AND METHODS}

Types, chemical composition, and manufacturers of the DA and denture base materials used in this study are listed in Table 1 .

\section{Sample fabrication:}

100 samples $(10 \mathrm{~mm} \times 10 \mathrm{~mm} \times 2 \mathrm{~mm})$ of two types of denture base resins were prepared. 50 samples for PMMA resin and 50 samples for UDMA resin.

PMMA specimens were prepared by investing pieces of modeling wax (Cavex- Holand BV) in stone plaster (LabStone- Dentsply) by conventional flasking procedure in metallic dental flask. After wax elimination the acrylic resin denture base material was mixed, packed within the plaster molds, and processed in a thermostatically controlled water bath according to the manufacturer's instructions. For UDMA (Eclipse) specimens, a silicon mould was created by investing wax into silicon material (Degoform plus- DeguDent GmbH, Germany). The silicon mould was lined with a separating agent (Al-Cote- Dentsply, USA), and warmed in the conditioning oven. Afterword, the pre-packed resin was adapted into the silicon mould using finger pressure. The exposed surface of UDMA specimen was lined with air barrier coating (Eclipse, Air

TABLE (1) Materials used in this study.

\begin{tabular}{|c|c|c|c|c|}
\hline Product Name & $\begin{array}{l}\text { Material } \\
\text { Type }\end{array}$ & Composition & Manufacturer & Batch no. \\
\hline $\begin{array}{l}\text { Corega Super } \\
\text { Cream }\end{array}$ & $\begin{array}{l}\text { Denture } \\
\text { adhesive }\end{array}$ & $\begin{array}{l}\text { Poly(methylvinylether/ } \\
\text { malic acid) sodium- } \\
\text { calcium mixed partial salt, petrolatum, cellulose } \\
\text { gum, paraffinumliquidum. }\end{array}$ & $\begin{array}{l}\text { Stafford- Miller(Dungarvan, } \\
\text { Irland) }\end{array}$ & V12353A \\
\hline $\begin{array}{l}\text { Corega Ultra } \\
\text { Powder }\end{array}$ & $\begin{array}{l}\text { Denture } \\
\text { adhesive }\end{array}$ & $\begin{array}{l}\text { Poly(methylvinylether/ } \\
\text { malic acid) sodium- } \\
\text { calcium mixed partial salt, cellulose gum, flavor }\end{array}$ & $\begin{array}{l}\text { Stafford- Miller(Dungarvan, } \\
\text { Irland) }\end{array}$ & N13032 \\
\hline $\begin{array}{l}\text { Olivafix } \\
\text { Cream }\end{array}$ & $\begin{array}{l}\text { Denture } \\
\text { adhesive }\end{array}$ & $\begin{array}{l}\text { Cellulose gum, OleaEuropea(Olive oil), Calcium/ } \\
\text { Sodium, PVM/MA copolymer, Hydrogenated } \\
\text { soybean oil, trihydroxystearin, silica, mentol, } \\
\text { lecithin, Citrus limonum, menthyl lactate. }\end{array}$ & $\begin{array}{l}\text { bonyf AG- (Liechtenstein. } \\
\text { EU)- Swiss }\end{array}$ & $41-27$ \\
\hline $\begin{array}{l}\text { Protefix } \\
\text { Cream }\end{array}$ & $\begin{array}{l}\text { Denture } \\
\text { adhesive }\end{array}$ & $\begin{array}{l}\text { Poly(methylvinylether/malic acid) sodium/ } \\
\text { calcium partial salt, carboxymethyl cellulose, } \\
\text { paraffin,vaseline, silica, menthol, azorubin, } \\
\text { p-hydroxy-benzoic acid methyl ester. }\end{array}$ & $\begin{array}{l}\text { QueisserPharma (Flensburg, } \\
\text { Germany) }\end{array}$ & 088072 \\
\hline Eclipse & $\begin{array}{l}\text { Denture } \\
\text { base resin }\end{array}$ & $\begin{array}{l}\text { Matrix: UDMA } \\
\text { Filler: silica, PMMA beads }\end{array}$ & Dentsply,New York, USA & 120612 \\
\hline Ecocryl-Hot & $\begin{array}{l}\text { Denture } \\
\text { base resin }\end{array}$ & $\begin{array}{l}\text { Powder: Methylmethacrylate-copolymer } \\
\text { Liquid: Methylmethacrylate- monomer }\end{array}$ & $\begin{array}{l}\text { Protechno, } \\
\text { Girona, Spain }\end{array}$ & $12-26964$ \\
\hline
\end{tabular}


Barrier Coating, Dentsply, USA) and polymerization was carried out in a curing unit (Eclipse, DentsplyUSA) for 10 minutes.

All the specimens were visually inspected and checked for absence of voids or porosity. Defected samples were discarded. The study specimens were prepared to the required dimensions by finishing discs and stones using hand piece at low speed. One side of the specimens was finished to a smooth surface using 280, 360 and 400 grit abrasive papers (Middle East Factory- K.S.A), followed by polishing on wet rag wheel with slurry pumice. All the specimens were prepared by the same operator.

All the test specimens were stored in distilled water at $37^{\circ} \mathrm{C}$ for 48 hours for residual monomer elimination. After that all the specimens were dried with air, numbered and the initial surface roughness was measured for the polished side of each specimen. Then the specimens of both groups were randomly divided into five subgroups $(n=10)$. Four test groups for immersion in four different DA and one control group for immersion in distilled water.

\section{Denture adhesive preparation:}

The denture adhesives tested in this study were dissolved in distilled water at percent solution consistent with expected conditions in the oral cavity, as recommended by earlier studies..$^{24,31}$ One gram of the four used DA (Table 1) was weighed and mixed with $10 \mathrm{ml}$ distilled water in a plastic container. After dilution with water the $\mathrm{pH}$ values of each denture adhesive was measured using $\mathrm{pH}$ meter (HANNA pH211- Woonsocket RI USA). Table 2 shows the measured $\mathrm{pH}$ values for the used DA.

TABLE (2) $\mathrm{pH}$ values of the denture adhesives.

\begin{tabular}{|l|c|}
\hline Denture Adhesive & $\mathrm{pH}$ values $\left(\right.$ at $22.5 \mathrm{C}^{\circ}$ ) \\
\hline Corega cream & $5.52 \pm 0.02$ \\
\hline Corega powder & $6.74 \pm 0.02$ \\
\hline Olive fix cream & $7.31 \pm 0.02$ \\
\hline Protefix cream & $6.13 \pm 0.02$ \\
\hline
\end{tabular}

Four test groups of PMMA and UDMA specimens were completely immersed in the four prepared DA and the fifth group specimens were immersed in a plastic container with $10 \mathrm{ml}$ distilled water. The immersion time was 16 hours per day. The containers were covered and stored in an incubator at $37^{\circ} \mathrm{C}$. Next the specimens were removed out of the prepared denture adhesives and rinsed under running water for 10 seconds. After that each group of samples were stored in distilled water for eight hours at room temperature. The adhesives were replaced and prepared daily and the procedure was repeated for 30 days.

\section{Measuring the surface roughness:}

The surface roughness $\left(R_{a}\right)$ values were measured using a contact profilometer device (MarSurf PS1- MahrGmbH. Göttingen- Germany) similar to previous investigations. ${ }^{32,33}$ The instrument complies with DIN EN ISO 3274 standards. The profilometer can measure small surface variations by moving a diamond stylus across the specimen surface (Figure 1). The tracing length of the instrument stylus was $5.6 \mathrm{~mm}$ and a cut-off of 0.8

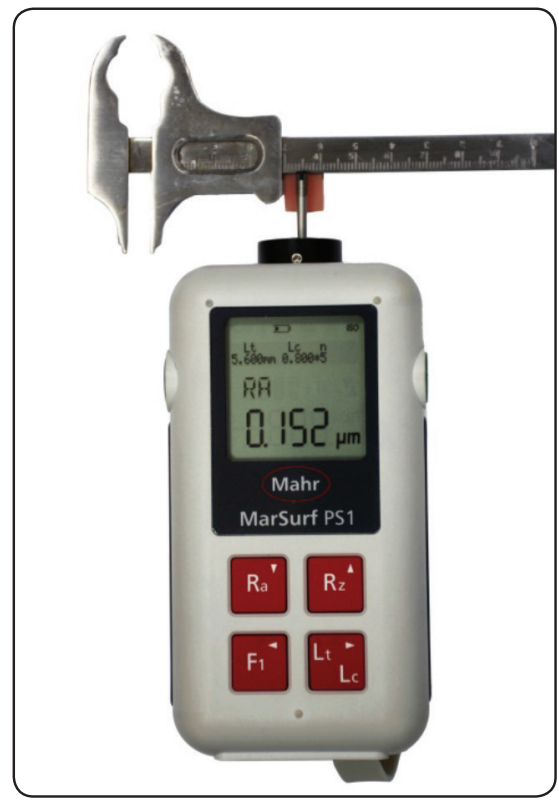

Fig. (1) Surface roughness measurement using pocket profilometer device 
$\mathrm{mm}$ at speed of $0.5 \mathrm{~mm} / \mathrm{s}$. $\mathrm{R}_{\mathrm{a}}$ value is the arithmetic average assigned to peaks and valleys of an area provided in $\mu \mathrm{m} . \mathrm{R}_{\mathrm{a}}$ is frequently used as a universal roughness parameter for general quality control. ${ }^{34}$

The base line $\mathrm{R}_{\mathrm{a}}$ measurements were taken for the polished side of each sample of the five study groups before immersion in the adhesives and distilled water. The stylus moved across the specimen surface and 3 lines were recorded with a distance of $1 \mathrm{~mm}$ between each scanning line. The mean value for the three readings of the $R_{a}$ was considered the $\mathrm{R}_{\mathrm{a}}$ value for each specimen.

After 30 days of immersion, the specimens were removed, washed with running water for 10 seconds, and dried with compressed air. The final $\mathrm{R}_{\mathrm{a}}$ of each test specimens was measured again as before immersion. The mean $\mathrm{R}_{\mathrm{a}}$ was calculated and tabulated in a special form.

\section{Yeast cells preparation:}

CA strain ATCC 24433 was used in this work. This strain was sub-cultured from a thawed suspension of ATCC 24433 strain as following: thaw the fungal strain in a water bath at $25-30^{\circ} \mathrm{C}$. Then immediately, wipe down the ampule with ethanol $(70 \%)$ and aseptically transfer $100 \mu \mathrm{L}$ of the content on to fresh yeast Pepton Dextrose Agar media (Hardy Diagmostic Cul Genex ${ }^{\mathrm{TM}}$ ). After 48 hours incubation at $37^{\circ} \mathrm{C}$, the cells were maintained at $4^{\circ} \mathrm{C}$ until further usage.

Prior to use in cell adhesion, $C A$ cells were transferred in to $10 \mathrm{ml}$ of Sabouraud's broth (Hardy Diagmostic Cul GenexTM) using sterilized cotton swap, and incubated at $37 \pm 2{ }^{\circ} \mathrm{C}$ overnight.

Then $10 \mathrm{ml}$ of the overnight broth culture at $0.5 \mathrm{McF}$ arland equivalents to $10^{7}$ Colony Forming Units (CFU/ml) was added to $90 \mathrm{ml}$ of Sabouraud's broth and further incubated at $37^{\circ} \mathrm{C}$ for 24 hours to attain a stationary phase.

\section{Adherence assay:}

In sterile Petri-dishes all denture base specimens were sterilized, the specimens of each group were then immersed in $10 \mathrm{ml}$ of the 24 hours broth culture with $C A$ (ATCC 24433) at $0.5 \mathrm{McFarland}$ scale for overnight at $37^{\circ} \mathrm{C}$. The specimens were removed using sterile forceps and rinsed gently twice for 15 seconds with phosphate buffered saline $(0.15 \mathrm{M}$, PH 7.2).

The microbial biofilm on the specimens was fixed using absolute methyl alcohol for one minute, the specimens were plotted on paper towel and stained using Gram's staining technique. ${ }^{35}$ (Figure 2)

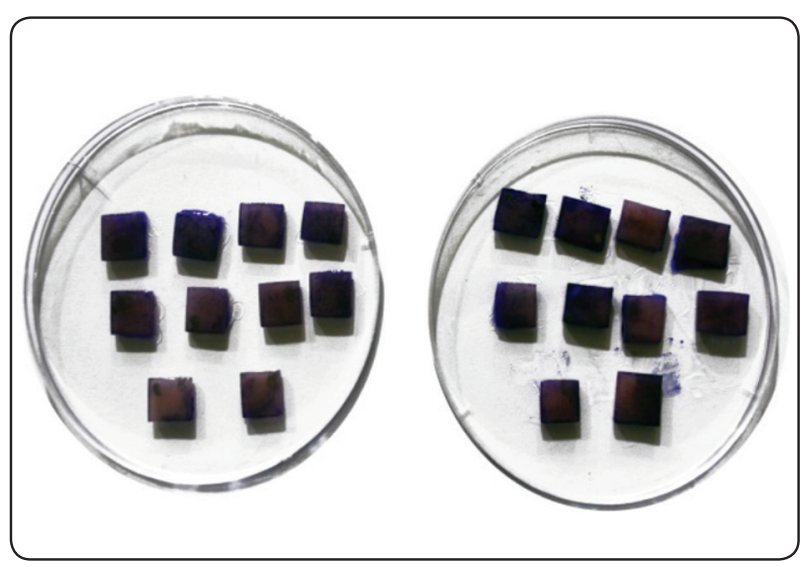

Fig. (2) Acrylic specimens with fixed biofilm

All samples were washed in phosphate buffered saline solution for 30 seconds by gentle agitation using bench top shaker (50 rpm) and examined by light microscopy under x1000 magnification. The adherent candida cells in five fields of view $\left(0.25 \mathrm{~mm}^{2}\right.$ per field) were counted and the results were expressed as yeast cells $/ \mathrm{mm}^{2}$ of each denture base samples.

\section{Statistical analysis:}

Individual $\mathrm{R}_{\mathrm{a}}$ and $\mathrm{CA}$ adhesion readings were calculated and tabulated. Statistical Package for Social Science (SPSS) computer software (SPSS 16.0, SPSS Inc. Chicago, USA) was used. $T$-test for 
paired observation was used to indicate any changes in $\mathrm{R}_{\mathrm{a}}$ after 30 days of immersion in the $\mathrm{DA}$ and control groups. Also, comparison of CA adhesion readings between all the study groups was performed using one way ANOVA with post hoc Tukey test at 95\% confidence interval. Finally, comparison in CA adhesion count between UDMA and PMMA resin groups was done using independent $T$-test. The level of significance was set at $P \leq 0.05$.

\section{RESULTS}

\section{Surface roughness $\left(\mathbf{R}_{\mathrm{a}}\right)$ :}

The mean differences in $\mathrm{R}_{\mathrm{a}}$ and standard deviation of the study groups are summarized in Table 3. The results showed that after 30 days of immersion in DA, there was an increase in the surface roughness for all test specimens.
The increase in $\mathrm{R}_{\mathrm{a}}$ in the Corega super cream groups for both UDMA resin and PMMA resin was statistically significant $(P<0.05)$. On the contrary, the increase in $\mathrm{R}_{\mathrm{a}}$ in the other DA groups and distilled water-exposed groups was statistically non-significant $(P>0.05)$.

\section{Candida albicans adhesion:}

The mean number and standard deviation of CA per specimen of the adhesive exposed groups as well as the distilled water group (control group) for both UDMA and PMMA resins are summarized in Table 4 . The results showed that the mean number of CA per specimen in the adhesive exposed groups was higher than that in the non-exposed group (control group) for both UDMA and PMMA resins. The differences in the Candida count between the UDMA specimens were not statistically significant.

TABLE (3) Changes in surface roughness values (mean value $\mathrm{SD} \pm$ ) for the study groups.

\begin{tabular}{|c|c|c|c|c|}
\hline \multirow{2}{*}{ Study groups } & \multicolumn{2}{|c|}{ UDMA } & \multicolumn{2}{c|}{ PMMA } \\
\cline { 2 - 5 } & $\Delta \mathrm{R}_{\mathrm{a}}$ Values $(\mu \mathrm{m})$ & $P$-value & $\Delta \mathrm{R}_{\mathrm{a}}$ Values $(\mu \mathrm{m})$ & $P$-value \\
\hline Corega cream group & $0.043(0.037)$ & $0.006^{*}$ & $0.01(0.011)$ & $0.023^{*}$ \\
\hline Corega powder group & $0.004(0.027)$ & 0.625 & $0.008(0.013)$ & 0.079 \\
\hline Olivafix Cream group & $0.003(0.035)$ & 0.835 & $0.002(0.055)$ & 0.916 \\
\hline Protefix Cream group & $0.006(0.011)$ & 0.118 & $0.007(0.016)$ & 0.178 \\
\hline Distilled water (control group) & $0.002(0.012)$ & 0.705 & $0.002(0.004)$ & 0.102 \\
\hline
\end{tabular}

*Denotes significant difference $(P<0.05)$

Table (4) Candida count (mean value \pm SD) attached to denture base materials after immersion in denture adhesives and distilled water.

\begin{tabular}{|c|c|c|c|}
\hline Adhesive type & UDMA Resin Candida count & PMMA Resin Candida count & $P$-Value \\
\hline Corega cream & $47.36 \pm 13.59$ & $62.00 \pm 21.90 *$ & 0.240 \\
\hline Corega powder & $47.08 \pm 10.28$ & $42.44 \pm 6.29$ & 0.414 \\
\hline Olivafix cream & $46.20 \pm 7.61$ & $36.52 \pm 16.00$ & 0.251 \\
\hline Protefix cream & $44.64 \pm 10.96$ & $42.40 \pm 11.25$ & 0.758 \\
\hline Control (Distilled water) & $37.84 \pm 5.64$ & $33.28 \pm 3.32$ & 0.158 \\
\hline
\end{tabular}

*Denotes significant - one way ANOVA with Tukey test. 
On the other hand the Candida count of Corega cream exposed group $(62.00 \pm 21.90)$ was statistically significant if compared with other groups in the PMMA resin specimens, as indicated by the one way ANOVA with post hoc Tukey test. Finally the differences in the Candida count between the specimens of both UDMA resin and PMMA resin groups were statistically non-significant $(P>0.05)$.

\section{DISCUSSION}

The extent to which DA may affect the denture surface integrity in term of change in surface roughness and its relation to CA adhesion is not yet clear. This study can be considered the first attempt to clarify the effect of 4 commercially available DA on surface roughness, and CA adhesion of two chemically different denture base materials. The null hypothesis that DA would not affect surface roughness of denture base resins, and CA adhesion, was partially rejected.

In the present investigation, The Corega super cream was the only DA material that affected the roughness of both types of denture base materials. This finding may be related to the low $\mathrm{pH}$ value of the Corega super cream DA (5.52) compared with other tested DA as presented in Table 2. Under acidic conditions, the polymer surface may be softened by loss of structural ions. ${ }^{14,15}$ This finding is in agreement with Koda et al who found that at lower $\mathrm{pH}$ conditions there was an increase in the concentration of MMA monomer leached from the denture base acrylic resin. ${ }^{16}$ Also, Jaeggi et al stated that under acidic condition restorative materials including composite resin may suffer degradation which can be predicted by change in the surface topography and roughness. ${ }^{17}$

In a study by Constantinescu et al the denture base acrylic resins showed a higher roughness when the $\mathrm{pH}$ was more acid. The authors related the changes in surface features and the increased $R_{a}$ to factors can cause salivary acidity. ${ }^{21}$ Furthermore
Love and Biswas recommended that DA with low $\mathrm{pH}$ values should not be used in an environment with natural teeth or remnants of natural teeth, because the prolonged contact of denture adhesive with tooth substance may dissolve hydroxyapatite crystals. ${ }^{31}$

The low $\mathrm{pH}$ can also change UDMA resin matrix by acting as a catalyst for the ester groups that are present in dimethacrylate monomers. This process may cause degradation of the polymer network and lead to a phenomenon known as plasticization that may change the surface properties of the resin..$^{18,19}$

The Increased $\mathrm{R}_{\mathrm{a}}$ of the Corega super cream exposed group may also be related to the presence of paraffinumliquidum. Among the studied DA, the Corega super cream is the only DA that contains the paraffinumliquidum in its composition. This mineral oil is added to the water soluble polymer powder to give it the paste form. The liquid paraffin may have a plasticizing effect causing plasticization of polymer chains, leading to material degradation by increased water sorption and solubility. ${ }^{20}$

In this study, the mean values of CA adherence to the adhesive exposed groups were more than that of non- exposed groups, and these findings may be related to the changes induced in the surface roughness of test specimens. However only Corega super cream exposed group of PMMA specimens, demonstrated significant increase in the number of CA adhesion compared with other test PMMA groups. This finding may be related to the significant increase in surface roughness in the Corega cream exposed group. This goes in line with study conducted by Nevzatoðlu et al who concluded that $\mathrm{R}_{\mathrm{a}}$ is positively correlated with adherence and colonization of fungi to the acrylic denture bases. ${ }^{22}$ In spite of the significant increase in $\mathrm{R}_{\mathrm{a}}$ of Corega cream exposed UDMA group, the increase in the CA adhesion was non-significant if compared with other test UDMA groups, this finding can be explained by presence of other factors rather than $\mathrm{R}_{\mathrm{a}}$, like 
wettability or surface free energy may affect fungi adhesion. Exposure of UDMA specimens to the DA may render the surface to be more hydrophobic, and, hence reduce the effect of surface roughness, so less cell adherence is expected. In previous studies a direct relationship between surface free energy and CA adhesion was reported. ${ }^{4,12}$

In the present investigation there was no statistically significant differences in the CA counts for PMMA groups if compared with UDMA groups, regardless if it was exposed to DA or not (control group), this finding contradicts with the result of study performed by Koch et al who found significant higher Candida count with UDMA (Eclipse) denture bases if compared with other heat cured PMMA denture base material. ${ }^{13}$ This disparity could be due to the use of different PMMA materials, in addition to different treatment done to the specimens. In Koch study the specimens was subjected to thermal cycling while in this study the specimens was exposed to DA. These differences in the treatment may induce changes in the surface properties of the denture base materials that may be critical for $\mathrm{CA}$ adhesion.

During interpretation of the results of this study the following limitations should be considered; first the DA used in one concentration, which not occur clinically because of the continuous dilution by saliva during denture wearing. However, this concentration could represent longer application time. Additionally, the study is limited in simulating the intraoral condition of temperature and $\mathrm{pH}$ fluctuations combined with the mechanical loading during masticatory function. Also the denture base surfaces used in the present study do not adequately represent the intaglio surface features of a denture in vivo. Finally, formation of single species CA under semi static incubation conditions in a thermally controlled device, this doesn't perfectly correspond to the oral cavity due to the lack of dynamic incubation conditions.

\section{CONCLUSION}

Within the limitations of this study it can be concluded that; some denture adhesives may influence the surface roughness of the denture base materials. Type of the denture base material may affect adhesion of Candida albicans. It appears that Candida albicans adhesion, in particular, is not necessarily increased on denture base materials that are exposed to denture adhesives.

\section{REFERENCES}

1. Oliveira MC, Oliveira VM, Vieira AC et al. In vivo assessment of the effect of an adhesive for complete dentures on colonisation of Candida species. Gerodontology 2010; 27: 303-7.

2. Richardson M, Lass-Florl C: Changing epidemiology of systemic fungal infections. Clin Microbiol Infect 2008, 14:5-24.

3. Morschhauser $\mathrm{J}$ : Regulation of multidrug resistance in pathogenic fungi. Fungal Genet Biol 2010, 47:94-106.

4. Ziad N. AL-Dwairi, Firas A. AL-Quran, Oraib Y. ALOmari. The effect of antifungal agents on surface properties of poly(methyl methacrylate) and its relation to adherence of Candida albicans. J Prosthodont Res 2012; 56: 272-80.

5. Cannon RD, Chaffin WL. Oral colonization by Candida albicans. Crit Rev Oral Biol Med. 1999;10:359-83.

6. Chandra J, Mukherjee PK, Leidich SD, Faddoul FF, Hoyer LL, Douglas LJ, Ghannoum MA. Antifungal resistance of candidal biofilms formed on denture acrylic in vitro. J Dent Res. 2001;80:903-8.

7. Ramage G, Tomsett K, Wickes BL, Lopez-Ribot JL, Redding SW. Denture stomatitis: a role for Candida biofilms. Oral Surg Oral Med Oral Pathol Oral Radiol Endod. 2004;98:53-9.

8. Branting C, Sund ML, Linder LE. The influence of Streptococcus mutans on adhesion of Candida albicans to acrylic surfaces in vitro. Arch Oral Biol. 1989;34:347-53.

9. Park SA, Blissett R, Susarla SM, Weber HP. Candida albicans adherence to surface-modified denture resin surfaces. J Prosthodont 2008;17:365-9.

10. Bridgett MJ, Davies MC, Denyer SP, Eldridge PR. In vitro assessment of bacterial adhesion to Hydromer-coated cerebrospinal fluid shunts. Biomaterials. 1993;14:184-8. 
11. Verheyen CC, Dhert WJ, de Blieck-Hogervorst JM, van der Reijden TJ, Petit PL, de Groot K. Adherence to a metal, polymer and composite by Staphylococcus aureus and Staphylococcus epidermidis. Biomaterials. 1993;14:383-91.

12. Minagi S, Miyake Y, Inagaki K, Tsuru H, Suginaka H. Hydrophobic interaction in Candida albicans and Candida tropicalis adherence to various denture base resin materials. Infect Immun 1985; 47:11-4.

13. Koch C1, Bürgers R, Hahnel S. Candida albicans adherence and proliferation on the surface of denture base materials. Gerodontology. 2013;30:309-13.

14. Suese K, Kawazoe T. Wear resistance of hybrid composite resin for crown material by the two-body sliding test. Dent Mater J. 2002;21:225-37.

15. Valinoti AC, Neves BG, Silva EM, Maia LC. Surface degradation of composite resins by acidic medicines and pH-cycling. J Appl Oral Sci. 2008;16:257-65

16. Koda T, Tsuchiya H, Yamauchi M, Ohtani S, Takagi N, Kawano J. Leachability of denture-base acrylic resins inartificial saliva. Dent Mater.1990; 6:13-6.

17. Jaeggi T, Gruninger A, Lussi A. Restorative therapy of erosion. Monogr Oral Sci 2006;20:200-14.

18. Miranda DA, Bertoldo CES, Aguiar FHB, Lima DANL, Lovadino JR. Effects of mouth rinse on Knoop hardness and surface roughness of dental composites after different immersion times. Braz Oral Res 2011;25:168-73.

19. Ferracane JL. Hygroscopic and hydrolytic effects in dental polymer networks. Dent Mater 2006; 22: 211-22.

20. Woodruff CW, Peck GE, Banker GS. Effect of environmental conditions and polymer ratio on water vapor transmission through free plasticized cellulose films. J Pharm Sci 1972;61:1956-9.

21. Constantinescu IR, Ursache M, Mardarez D. Effect of pH on the surface roughness of heat cured denture base acrylic resins. Rev Med Chir Soc Med Nat Iasi.2007; 2: 477-81.

22. Nevzatoðlu EU, Ozcan M, Kulak-Ozkan Y, Kadir T. Adherence of Candida albicans to denture base acrylics and silicone-based resilient liner materials with different surface finishes. Clin Oral Investig 2007; 11:231-6.
23. Kalra P, Nadiger R, Shah FK. An investigation into the effect of denture adhesives on incisal bite force of complete denture wearers using pressure transducers- a clinical study. J Adv Prosthodont 2012; 4: 97-102.

24. Zhao K, Cheng XR, Chao YL, Li ZA, Han GL. Laboratory evaluation of a new denture adhesive. Dent Mater 2004; 20: 419-24.

25. Adisman IK. The use of denture adhesives as an aid to denture treatment .J Prosthet Dent 1989; 62:711-5.

26. Stafford GD, Russell C. Efficiency of denture adhesives and their possible influence on oral microorganisms. J Dent Res 1971;50:832-6.

27. Makihira S, Nikawa H, Satonobu SV et al. Growth of Candida species on commercial denture adhesives in vitro. Int J Prosthodont 2001;14:48-52.

28. Kim E, Driscoll CF, Minah GE. The effect of a denture adhesive on the colonization of Candida species in vivo. $\mathrm{J}$ Prosthodont 2003;12:187-91.

29. Sampaio-Maia B, Figueiral MH, Sousa-Rodrigues P, Fernandes MH, Scully C. The effect of denture adhesives on Candida albicans growth in vitro. Gerodontology 2012; 29:348-56.

30. Arendorf TM, Walker DM. Denture stomatitis: a review. J Oral Rehabil 1987; 14:217-27.

31. Love WB, Biswas S. Denture adhesives-pH and buffering capacity. J Prosthet Dent 1991;66:356-60.

32. Machado AL, Giampaolo ET, Pavarina AC, Jorge JH, Vergani CE. Surface roughness of denture base and reline materials after disinfection by immersion in chlorhexidine or microwave irradiation. Gerodontology 2012;29:375-82.

33. Ayaz EA, Altintas SH, Turgut S. Effects of cigarette smoke and denture cleaners on the surface roughness and color stability of different denture teeth. J Prosthet Dent 2014; 112:241-8.

34. Gadelmawla ES, Koura MM, Maksoud TMA, Elewa IM, Soliman HH. Roughness parameters. Journal of Materials Processing Technology 2002;123:133-45.

35. Raut J. S , Ravikumar B S , Nitin M C , and Sankunny M K (2014) Phenylpropanoids of Plant Origin as Inhibitors of Biofilm Formation by Candida albicans. J Microbiol Biotechnol 2014; 24:1216-25. 